\title{
O ensino de Gestão da Produção utilizando a Aprendizagem Baseada em Problemas (ABP) e a Simulação de Eventos Discretos (SED)
}

\author{
Production Management teaching using Problem-Based Learning (PBL) and \\ Discrete-Event Simulation (DES)
}

\author{
Heráclito Lopes Jaguaribe Pontes \\ Universidade Federal do Ceará \\ hjaguaribe@ufc.br
}

Bruno Holanda do Amaral (iD https://orcid.org/0000-0003-3587-6005 Universidade Federal do Ceará brunoholandaamaral@gmail.com

\author{
Maxweel Veras Rodrigues (iD https://orcid.org/0000-0003-1999-6832 \\ Universidade Federal do Ceará \\ maxweelveras@gmail.br
}

\section{Resumo}

Atualmente, novos desafios são exigidos no mercado de trabalho, como por exemplo, maior visão sistêmica e capacidade de resolução de problemas, com isso, as instituições de ensino têm sido estimuladas a aplicar metodologias ativas de aprendizagem. Este estudo aborda uma aplicação, em conjunto, da Simulação de Eventos Discretos (SED), através do Software Flexsim, e da Aprendizagem Baseada em Problemas (ABP) como instrumentos de ensino de gestão da produção para alunos de um curso de Engenharia de Produção. Para isso, foi desenvolvida uma metodologia com três níveis de problemas a serem solucionados em equipes e utilizando o simulador. Cada nível funcionou como um ciclo de aprendizagem da ABP. A avaliação do experimento apontou que $100 \%$ dos alunos concordaram que a metodologia ABP estimulou o aprendizado em sala de aula e trouxe resultados positivos para a disciplina optativa intitulada "Aplicações de Simulação em Sistemas de Produção e Logística". Na pesquisa realizada, $73,7 \%$ dos alunos concordaram que estavam aptos a aplicar a simulação para a resolução de problemas, após o experimento. O programa Flexsim recebeu nota média geral muito boa, apresentando o melhor desempenho no critério de interface gráfica. Finalmente, a nota média para a aplicação das metodologias foi excelente, caracterizando um ótimo resultado e evidenciando os benefícios que estas poderiam trazer se utilizadas com mais frequência e em outras disciplinas do curso.

Palavras-chave: Aprendizagem. Aprendizagem Baseada em Problemas. Simulação. Produção.

\begin{abstract}
Recently, new challenges have been required in the labor market, such as greater systemic vision and problem-solving abilities. As a result, educational institutions have been encouraged to apply
\end{abstract}


active learning methodologies. This study addresses a joint application of Discrete-Event Simulation (DES), through the Flexsim Software, and Problem-Based Learning (PBL) as production management teaching tools for students in a Production Engineering course. To this end, a methodology was developed with three levels of problems to be solved in teams through the use of the simulator. Each level functioned as a PBL learning cycle. The experiment evaluation showed that $100 \%$ of the students agreed that the PBL methodology stimulated learning in the classroom and brought positive results to the elective course entitled "Simulation Applications in Production and Logistics Systems". In the survey, $73.7 \%$ of the students agreed that, after the experiment, they felt capable in applying the simulation to solve problems. The Flexsim program received a very good overall average score, with the best performance being in the graphical interface criterion. Finally, the average score for the application of the methodologies was excellent, which characterizes a great result and highlights the benefits that these could bring if used more frequently and in other course subjects.

Keywords: Learning. Problem-Based Learning. Simulation. Production.

\section{Introdução}

Atualmente, o nível de globalização do mundo exige que as organizações se dediquem a melhorar suas operações e serviços prestados para se manterem competitivas no mercado. Ambientes de trabalho complexos e o encarecimento dos recursos têm levado as organizações a procurar novas soluções em produtividade e principalmente, por profissionais mais capacitados e multidisciplinares (DO AMARAL, 2018).

A preparação profissional é uma função essencial que as Instituições de Ensino Superior (IES) exercem. Conforme Santana (2011), a sociedade tem a expectativa de que as universidades preparem profissionais competentes, como colocam Heinig e Franzen (2013), isso implica em mudanças na formação acadêmica, o que leva à necessidade de se repensar a forma de transmitir conhecimento nos cursos de engenharia.

Segundo as Diretrizes Curriculares Nacionais do Curso de Engenharia (BRASIL, 2002), Art. 3, o egresso deve estar apto a desenvolver novas tecnologias de acordo com as atualidades, avaliar criticamente a operação, conduzir experimentos, analisar dados e resultados, e principalmente, estar apto a resolver problemas que possam surgir neste processo. Desta forma, o curso de engenharia tem a função de estimular essas habilidades a partir de projetos com complexidade crescente, o que exige um planejamento direcionado das instituições e a escolha da metodologia a ser utilizada (MASSON, 2012), que deverá estimular os estudantes à proatividade, tomar decisões e avaliar os resultados, experimentando, assim, as vertentes do problema (MORAN, 2015).

Apesar do que foi exposto, existem problemas ligados ao processo de formação em Engenharia, como a alienação dos estudantes no ciclo básico, a ausência de integração entre teoria e prática e a dificuldade em promover conhecimentos além dos técnicos e científicos no contexto curricular (RIBEIRO, 2008).

Para Borges e Almeida (2013), a formação dos engenheiros não pode mais ser apenas técnica; é preciso que outras habilidades também sejam desenvolvidas, tais como atitude empreendedora e capacidade de inovação, de gestão, de comunicação, de liderança e de exercer funções em equipes multidisciplinares. $O$ ensino em engenharia deve abranger planejamento, elaboração e implementação, 
adequando os estudantes e futuros profissionais a uma visão de interação de aprendizagem e vivência do exercício profissional.

Neste contexto, as instituições têm sido estimuladas a adaptarem sua forma de transmitir conhecimento, direcionando os estudantes para a solução de problemas reais e rompendo com estruturas engessadas e modelos de ensino tradicionais, nos quais os alunos assumem o papel de indivíduos passivos.

Já existem várias alternativas válidas para conciliar a apresentação de um volume crescente de conhecimentos técnicos e científicos à necessidade de trabalhar habilidades e atitudes. Dentre, podem ser citadas a Aprendizagem Baseada em Problemas (ABP) (RIBEIRO, 2008) e a Simulação de Eventos Discretos (SED), que conforme Khalil (2012) é de grande utilidade para a maior interatividade, compreensão de conceitos e dinamismo em sala de aula.

Este trabalho tem como objetivo aplicar a SED e a ABP no apoio ao ensino do conteúdo de gestão da produção evidenciando os resultados do uso de uma metodologia ativa em sala de aula, bem como a percepção dos alunos ao longo da experimentação.

Nesse sentido, a contribuição desse estudo é aplicar e analisar uma metodologia ativa com o uso de ABP e SED, a partir de uma experimentação em três diferentes níveis, com alunos de um curso de engenharia de produção.

\section{Revisão da Literatura}

Nessa seção serão detalhados os principais conceitos e técnicas utilizados no desenvolvimento do trabalho, assim como as bibliografias estudadas.

\section{Gestão da Produção}

A gestão da produção ocupa-se da atividade de gerenciamento estratégico dos recursos escassos (humanos, tecnológicos, informacionais e outros), de sua interação e dos processos que produzem e entregam bens e serviços, visando atender a necessidades e/ou desejos de qualidade, tempo e custo de seus clientes. (CORRÊA; CORRÊA, 2017, p.4)

A gestão da produção lida com processos para produzir bens e serviços que as pessoas utilizam todos os dias. Ao escolher as técnicas e estratégias de produção apropriadas e consistentes, os gestores podem projetar e operar processos que dão vantagem competitiva às empresas (KRAJEWSKI; RITZMAN; MALHOTRA, 2009).

Os processos possuem insumos e geram resultados aos clientes. De forma que a primeira responsabilidade de qualquer equipe de gestão da produção é entender quais são os objetivos organizacionais, traduzindo-os em termos de implicações para o objetivo de desempenho específico como: custo, qualidade, velocidade, flexibilidade e conformidade (SLACK et al., 2009).

\section{Utilização da Simulação de Eventos Discretos (SED) no Ensino}

Kelton et al. (2010) afirmam que a simulação é o processo de projetar um modelo computacional de um sistema real e conduzir experimentos, com o propósito de entender seu comportamento e/ou avaliar estratégias para sua operação.

Para Stivari e Gameiro (2013), a SED baseia-se na geração de eventos e é o modelo mais utilizado na prática. Para eles, uma vez que o sistema estiver descrito e 
modelado, serão conhecidas todas as atividades e entidades envolvidas. Cada evento significa o início ou fim de uma atividade, podendo ser perfeitamente caracterizado e uma lista cronológica de todos os eventos.

A simulação pode ser utilizada com fins educacionais para melhorar as práticas pedagógicas em cursos de engenharia: possibilitando o estudo e experimentação de complexas interações internas de um sistema; entendendo algumas variações no meio ambiente e identificar seus efeitos em todo o sistema; usando experiências com novas situações, sobre as quais se tem pouca ou mesmo nenhuma informação; servindo como um primeiro teste para se delinearem novas políticas e regras de decisão para a operação de um sistema, antes de experimentá-la no sistema real (KHALIL, 2012).

Rangel et al. (2012) descrevem dois modelos de simulação construídos para demonstrar a possibilidade de utilização de softwares de simulação de eventos discretos como um ambiente de treinamento de lógicas de controle automático de processos industriais. No experimento foi efetuada a integração de um modelo de simulação construído recebendo sinal de comando de um Controlador Lógico Programável (CLP). O ambiente virtual proposto, oriundo do modelo de simulação, possibilitou a realização de diferentes testes de lógicas de controle.

\section{Utilização de Aprendizagem Baseada em Problemas (APB) no Ensino de Engenharia}

ABP é uma metodologia ativa de aprendizagem que se baseia em experiências. Nela os estudantes são estimulados a realizar a investigação, explicação e a resolução de problemas significativos, aqueles os quais os alunos vejam sentido, ou seja, que observam a possibilidade de se depararem com eles no decorrer de suas carreiras (RIBEIRO, 2008).

Na ABP, o professor assume o papel de facilitador, orientando os alunos através de ciclos de aprendizado, diferentemente da metodologia tradicional, onde ele é exclusivamente detentor e transmissor do conhecimento (HMELO-SILVER, 2004).

Segundo Echavarria (2010), na ABP, o ponto de partida do processo de aprendizagem é o problema em si. A metodologia é centrada nos alunos, considerando que eles usam suas próprias experiências particulares e interesses; é baseada em atividades porque requer a tomada de decisões e pesquisa por parte dos alunos e é baseada na aprendizagem em grupos, pois devido ao processo ser realizado em equipe, eles aprendem juntos. Para o autor, a ABP trabalha diferentes aspectos da estrutura, processo e metas, os quais permitem uma distinção interessante entre o método empregado e as estratégias que foram utilizadas na solução dos problemas.

No ensino de engenharia, o processo de resolução do problema é complexo, frequentemente resulta em mais de uma possibilidade e implica a confecção de alguma solução concreta, como por exemplo, maquetes, protótipos e modelos. Esse processo requer tempo e conhecimentos conceituais, demandando muito esforço dos estudantes (RIBEIRO, 2008).

$\mathrm{A} A \mathrm{ABP}$ se torna muito importante à medida que os cursos de engenharia necessitam promover habilidades (trabalho em grupo, comunicação oral, escrita e resolução de problemas) e atitudes (ética, responsabilidade profissional e social, adaptabilidade e disposição para a aprendizagem contínua e autônoma), além de garantir base 
conceitual sólida aos alunos. Por isto, muitos cursos de engenharia mudaram seus métodos do tradicional para a ABP, embora esta prática ainda esteja longe de ser largamente utilizada (RIBEIRO, 2008).

$\mathrm{Na}$ utilização da metodologia ABP pelo curso de Engenharia de Produção da Universidade de Brasília, descrita por Monteiro (2011), a instituição adotou a metodologia no ano de $2011 \mathrm{com}$ a implantação gradual de sete disciplinas, Projetos de Sistema de Produção (PSP1 a PSP7). A disciplina PSP1 foi estruturada com a divisão da classe em grupos de cinco alunos, cabendo a cada grupo a definição de um projeto (problema) e a direção a ser tomada para a solução. Para cada grupo foi atribuído um tutor que era responsável pela aderência ao objeto do projeto e era o elemento de ligação entre o grupo e a coordenação da disciplina. Em pesquisa feita após o término da disciplina, $71 \%$ dos alunos que participaram perceberam melhoras no seu desempenho acadêmico após a mudança de metodologia.

Escrivão Filho e Ribeiro (2009) relatam, em estudo, uma experiência bem-sucedida de aplicação do método ABP, na disciplina de "Teorias da Administração", em cursos de Engenharia da Escola de Engenharia de São Carlos. No experimento, os alunos formaram grupos de quatro ou cinco membros com desempenho rotativo de papéis de líder, redator e porta-voz. O grupo devia apresentar a solução do problema em produtos variados, como relatório escrito em duas páginas, apresentação oral e criação de esquema visual em cartazes. O resultado da adoção parcial da ABP foi avaliado como bom por $90 \%$ dos participantes.

\section{Metodologia}

O trabalho foi desenvolvido num laboratório de simulação de uma IES pública do Nordeste Brasileiro, durante três turmas distintas da disciplina optativa "Aplicações de Simulação em Sistemas de Produção e Logística". Ao todo, participaram 20 alunos graduandos em Engenharia de Produção, de diversos períodos letivos e a experimentação teve duração média de 30 dias. As etapas da metodologia estão apresentadas na Figura 1. 
Figura 1 - Etapas da metodologia

\begin{tabular}{lll}
\hline 1 & - Aula Introdutória \\
\hline 3 & - Apresentação do Software Flexsim \\
\hline 4 & - Treinamento Básico no Flexsim \\
\hline 5 & - Nível 1: Organizando o processo \\
\hline 6 & - Nível 2: Problemas com funcionários \\
\hline 7 & - Nível 3: Aumento do mix de produtos \\
\hline & \\
\hline
\end{tabular}

Fonte: Elaboração própria (2020)

\section{Aula Introdutória}

Inicialmente, os conceitos básicos necessários à compreensão da disciplina foram apresentados aos alunos, através de uma aula expositiva. Essa abordagem inicial mostrou-se necessária, visto que a disciplina "Simulação em Sistemas de Produção e Logística" é um componente optativo à grade curricular do curso em questão e não há disciplinas prévias que abordem a metodologia.

A aula introdutória foi ministrada pelo professor da disciplina com apoio de alunos monitores, que relataram suas experiências com a simulação. Na ocasião, foram abordados os seguintes temas: conceitos de simulação; características da simulação; tipos e modelos de simulação; simulação de eventos discretos; simuladores; etapas do desenvolvimento de uma simulação e; aplicações da simulação na educação.

\section{Apresentação do Software Flexsim}

A segunda etapa da metodologia também foi caracterizada por uma aula expositiva, onde se apresentou aos estudantes o software a ser utilizado nas simulações, o Flexsim. Os pontos abordados, nessa etapa, foram: recursos e limitações do software; o ambiente 3D e os princípios básicos de usabilidade do software; ferramentas especiais oferecidas pelo software e; suas aplicações e; aplicações do software. Segundo Chen et al. (2013), o software Flexsim é uma integração típica entre a tecnologia de realidade virtual e a simulação orientada a objetos discretos.

Nesta etapa, também foram apresentados projetos utilizando o Flexsim, desenvolvidos pelos alunos monitores. O objetivo principal era tornar claro para os alunos as várias possibilidades de aplicação da ferramenta e seu funcionamento 
prático, despertando o interesse dos participantes. A utilização de aulas expositivas na metodologia do experimento foi encerrada neste ponto.

\section{Treinamento Básico no Flexsim}

Nesta etapa, os alunos foram iniciados tecnicamente no simulador. O treinamento ocorreu no laboratório da IES, possibilitando uma abordagem prática do conteúdo e aos alunos trabalharem individualmente ou em duplas. A duração desta etapa foi de 8 horas.

O material didático adotado foi a apostila "Introdução ao Flexsim V.01" desenvolvida por bolsistas e professor do próprio laboratório, experientes no software, que também auxiliaram nesta etapa como monitores, acompanhando a resolução do material pelos alunos e tirando possíveis dúvidas. A apostila foi estruturada em sete tópicos, os quais são considerados etapas essenciais para a simulação de problemas de baixa complexidade. Os objetivos de cada tópico estão descritos no Quadro 1.

Quadro 1 - Tópicos do treinamento inicial e seus objetivos

\begin{tabular}{|l|l|l|}
\hline \multicolumn{2}{|c|}{ Tópico } & \multicolumn{1}{c|}{ Objetivo(s) } \\
\hline 1. Iniciando o Flexsim & Explicar como criar um modelo. \\
\hline 2. Selecionando Unidades & $\begin{array}{l}\text { Apresentar quais são e como devem ser parametrizadas } \\
\text { as unidades da simulação, bem como onde estão } \\
\text { dispostos os principais botões e abas do simular. }\end{array}$ \\
\hline 3. Componentes da Simulação & $\begin{array}{l}\text { Apresentar os objetos utilizados na simulação: flowitens, } \\
\text { recursos fixos e os executores de tarefas. }\end{array}$ \\
\hline 4. Inserindo Objetos no Modelo & $\begin{array}{l}\text { Inserir os objetos listados anteriormente no ambiente de } \\
\text { simulação. }\end{array}$ \\
\hline 5. Editando Objetos & $\begin{array}{l}\text { Apresentar quais parâmetros dos objetos inseridos são } \\
\text { possíveis modificar e como realizar a mudança. }\end{array}$ \\
\hline 6. Realizando Conexões & $\begin{array}{l}\text { Conectar os objetos gerando um fluxo e diferenciar quais } \\
\text { os tipos de conexão. }\end{array}$ \\
\hline 7. Modelos & $\begin{array}{l}\text { Utilizar os conhecimentos das outras etapas para a } \\
\text { criação dos exemplos propostos. }\end{array}$ \\
\hline
\end{tabular}

Fonte: Elaboração própria (2020)

\section{Construção do Problema}

Nessa etapa, inicialmente foi desenvolvida uma pesquisa bibliográfica em livros e materiais que abordassem exercícios e problemas envolvendo a gestão da produção. Durante a busca, foram encontrados na literatura vários artigos que apontavam diversas vantagens em utilizar a simulação em conjunto com a análise de layout, assim a busca foi direcionada para este tema.

Outra motivação para a definição da temática do problema foi a capacidade de tornar a dinâmica de simulação envolvente e atrativa aos participantes, que é observada no estudo de layouts, onde as alterações na disposição virtual dos objetos impactam diretamente os resultados do experimento, diferentemente de problemas mais numéricos. O problema, também, deveria permitir ser adaptado em vários níveis de dificuldade e representar uma situação próxima à realidade das empresas e práticas da engenharia de produção.

Como resultado da pesquisa, foi encontrado um problema de layout do livro de Araújo (2002). O problema abordava o processo de recebimento e expedição de mercadorias de uma empresa, onde havia claros problemas na disposição do arranjo físico dos postos de trabalho. 
Encontrado o problema base, foram necessárias pequenas mudanças no processo original, de forma a melhor a adaptação para o software. O resultado foi o processo e o mapofluxograma apresentados no Quadro 2 e Figura 2.

Quadro 2 - Descrição das etapas do fluxo de mercadorias

\begin{tabular}{|c|c|}
\hline Etapas & Descrição \\
\hline 1. & $\begin{array}{l}\text { A mercadoria dá entrada no departamento de recebimento. Carolina, recepcionista do } \\
\text { andar, recebe a mercadoria. }\end{array}$ \\
\hline 2. & A recepcionista do andar leva a mercadoria até o balcão. \\
\hline 3. & $\begin{array}{l}\text { César, balconista, recebe a mercadoria e a leva para o conferente, digita e identifica o } \\
\text { pedido e confere a mercadoria com o pedido. }\end{array}$ \\
\hline 4. & $\begin{array}{l}\text { A mercadoria, juntamente com a nota fiscal, é enviada ao funcionário Luís, que } \\
\text { confere e assina o canhoto da NF. }\end{array}$ \\
\hline 5. & A mercadoria e a NF são enviadas ao funcionário Paulo, que verifica a soma da NF. \\
\hline 6. & $\begin{array}{l}\text { A mercadoria e a NF são entregues à funcionária Alice, que confere os valores da } \\
\text { nota com o pedido, abre o arquivo correspondente e transmite os dados à unidade } \\
\text { competente. }\end{array}$ \\
\hline 7. & Toda a documentação é levada ao gerente, que redige a autorização de pagamento. \\
\hline 8. & $\begin{array}{l}\text { A autorização de pagamento é encaminhada ao funcionário que faz a correspondente } \\
\text { digitação, imprime e passa ao assistente. }\end{array}$ \\
\hline 9. & $\begin{array}{l}\text { O assistente lê e verifica. Quando não há erros, manda então a autorização com os } \\
\text { dados necessários para a funcionária Amanda. }\end{array}$ \\
\hline 10. & $\begin{array}{l}\text { A funcionária Amanda recebe, digita um formulário de autorização de pagamento e } \\
\text { envia para a supervisora Alessandra, juntamente com a autorização assinada pelo } \\
\text { gerente. }\end{array}$ \\
\hline 11. & $\begin{array}{l}\text { A supervisora Alessandra recebe, confere e assina o formulário e a autorização, } \\
\text { enviando-os para Vânia, auxiliar de escritório. }\end{array}$ \\
\hline 12. & $\begin{array}{l}\text { Vânia recebe o formulário e a autorização, carimba as cópias e o original e leva com a } \\
\text { mercadoria para Juarez, o arquivista. }\end{array}$ \\
\hline 13. & $\begin{array}{l}\text { Juarez, o arquivista, recebe e separa as cópias grampeadas, depois grampeia uma } \\
\text { cópia na mercadoria. }\end{array}$ \\
\hline 14. & Juarez realiza o arquivamento físico das cópias. \\
\hline 15. & $\begin{array}{l}\text { Adriana, então, encaminha as cópias e a autorização à tesouraria e a mercadoria ao } \\
\text { almoxarifado. }\end{array}$ \\
\hline
\end{tabular}

Fonte: Adaptado de Araújo (2002) 


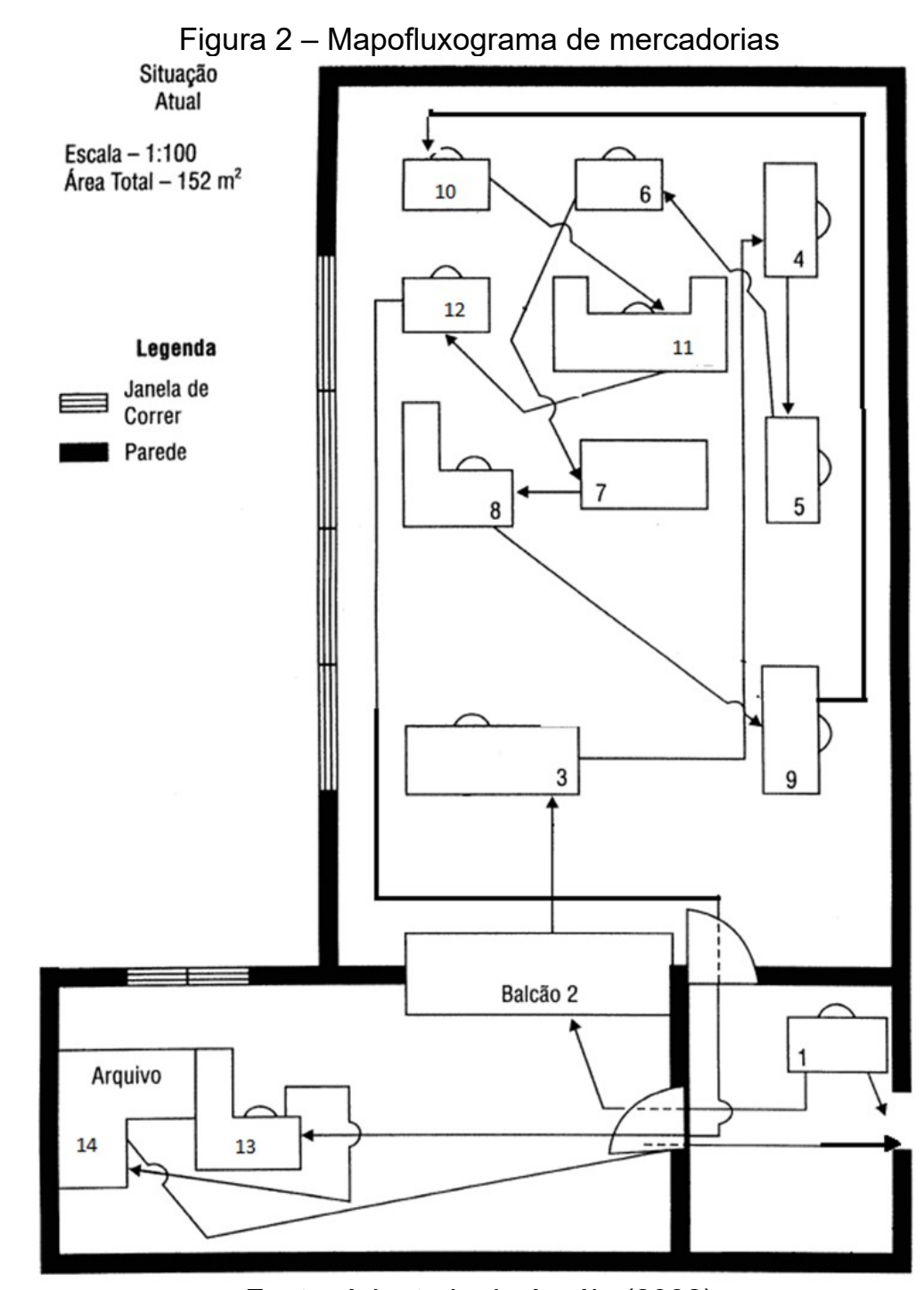

Fonte: Adaptado de Araújo (2002)

O ambiente virtual no programa Flexsim foi desenvolvido a partir da criação da planta baixa, baseado no mapofluxograma da Figura 2, e da mobília em 2D, no programa Autocad. Após o desenho 2D, a planta e mobília foram levadas ao programa Sketchup, para a criação do 3D.

Os blocos em 3D então foram importados para o Flexsim e organizados de acordo com o layout do problema. Foram inseridos alguns elementos figurativos como quadros e plantas, de forma a tornar o ambiente 3D mais lúdico (Figuras 3 e 4). 
Figura 3 - Layout 3D da empresa no Flexsim (perspectiva lateral)

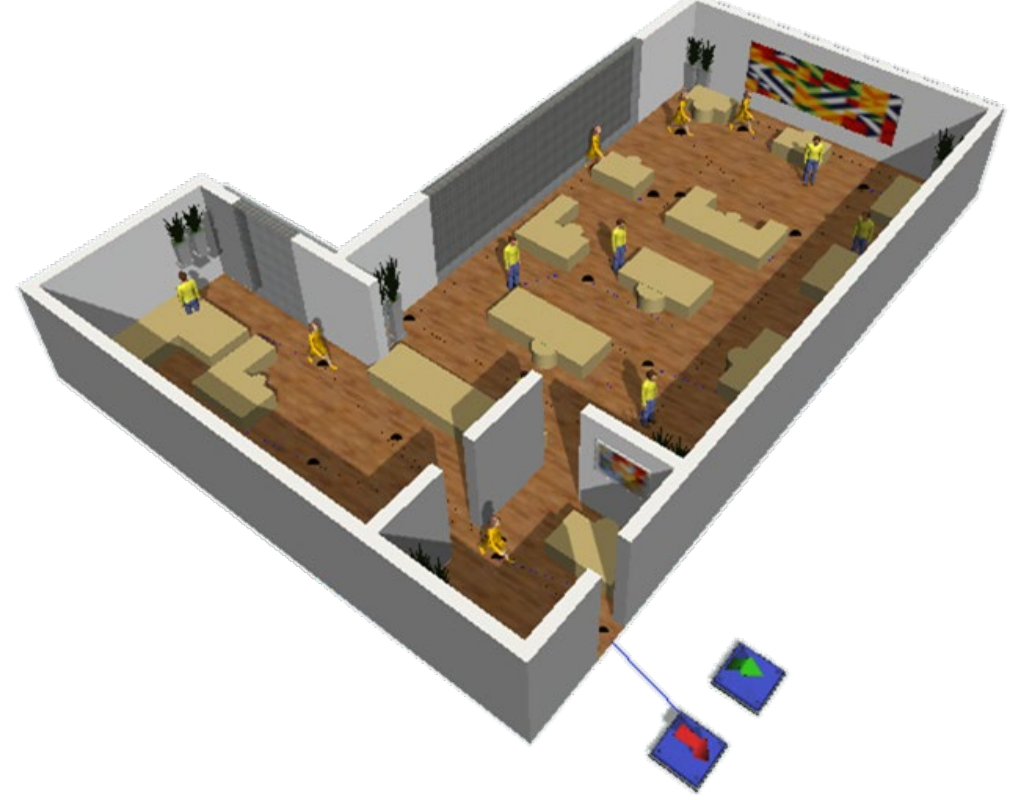

Fonte: Elaboração própria (2020)

Figura 4 - Layout 3D da empresa no Flexsim (vista superior)

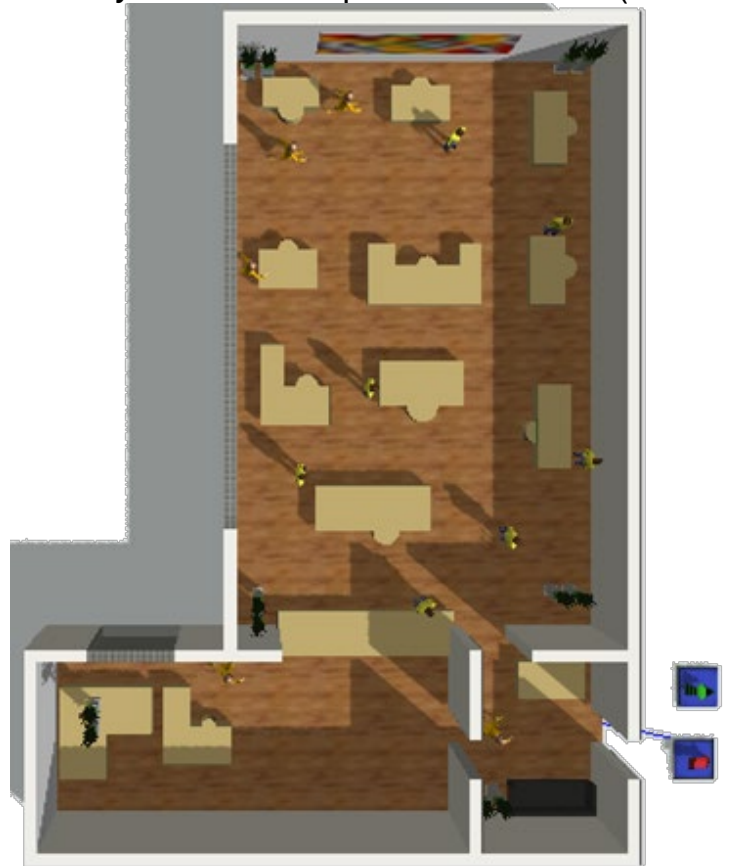

Fonte: Elaboração própria (2020)

Construído o ambiente virtual, chegou-se à etapa de simulação. Neste ponto, foi necessária a definição de algumas regras iniciais e parâmetros para o experimento, visto que a simulação deveria indicar um problema a ser resolvido pelos alunos. Assim, foram testados alguns parâmetros para as variáveis: distribuição de chegada das mercadorias, tempo de processamento em cada posto de trabalho e tempo de simulação. Os valores escolhidos e mais algumas condições necessárias ao bom desempenho da simulação foram enumeradas como regras (Quadro 3), que além de direcionar os alunos, também serviram com padrão para que todas as equipes trabalhassem sob as mesmas condições. 
Quadro 3 - Regras da simulação e descrições

\begin{tabular}{|c|c|}
\hline Regra & Descrição \\
\hline 1. & $\begin{array}{l}\text { Na simulação, todos os objetos "funcionários" devem ser nomeados e os objetos } \\
\text { "postos de trabalho" devem ser numerados de acordo com o mapa do processo. }\end{array}$ \\
\hline 2. & $\begin{array}{l}\text { O percurso que os funcionários irão percorrer dentro do escritório deve ser condizente } \\
\text { com as possibilidades reais. Ex. Não é permitido criar caminhos onde os funcionários } \\
\text { atravessem paredes ou móveis. }\end{array}$ \\
\hline 3. & $\begin{array}{l}\text { Os objetos "balcão" e "arquivo" devem ser considerados como estoques. A escolha do } \\
\text { tipo de recurso fixo dos outros postos de trabalho fica a cargo da equipe. }\end{array}$ \\
\hline 4. & $\begin{array}{l}\text { O parâmetro tempo deve estar em segundos e o limite da simulação deve ser } 21.600 \\
\text { segundos, caracterizando } 6 \text { horas de trabalho. }\end{array}$ \\
\hline 5. & $\begin{array}{l}\text { Os objetos decorativos, que compõe a simulação apenas para fins lúdicos, podem ser } \\
\text { movidos de local. }\end{array}$ \\
\hline 6. & Os funcionários participam tanto do transporte como do processamento da mercadoria. \\
\hline 7. & Na simulação, deverá haver uma dashboard com os indicadores requeridos. \\
\hline 8. & $\begin{array}{l}\text { O tempo de chegada da mercadoria segue uma distribuição exponencial de } 20 \mathrm{~s} \text {, sem } \\
\text { desvios. }\end{array}$ \\
\hline 9. & A capacidade máxima do balcão são 1000 mercadorias. \\
\hline 10. & $\begin{array}{l}\text { O tempo de operação de cada posto de trabalho segue uma distribuição normal de } 10 \\
\text { s, sem desvios. }\end{array}$ \\
\hline 11. & A mercadoria deve ser representada por uma caixa de cor branca. \\
\hline 12. & $\begin{array}{l}\text { A mercadoria deverá ser levada de um posto de trabalho para outro por um } \\
\text { funcionário, obrigatoriamente. }\end{array}$ \\
\hline 13. & Não há restrição quanto à posição dos móveis. \\
\hline
\end{tabular}

Fonte: Elaboração própria (2020)

Ao fim da simulação, foram extraídas as variáveis e indicadores resultantes, os quais deviam ser melhorados pelos estudantes ao longo dos níveis. No Quadro 4, estão representadas as três variáveis principais e seus resultados.

O número de saídas foi bem inferior à quantidade de entrada $(68,85 \%$ do total), resultado do acúmulo de mercadorias nos estoques, chegando à quantidade de 259 unidades, fora os itens em processo nos postos de trabalho.

Quadro 4 - Resultado das variáveis após a simulação

\begin{tabular}{|l|c|}
\hline \multicolumn{1}{|c|}{ Variável } & Quantidade \\
\hline Número de entrada de mercadorias. & 870 \\
\hline Número de saída de mercadorias. & 599 \\
\hline Estoque máximo no balcão. & 259 \\
\hline
\end{tabular}

Fonte: Elaboração própria (2020)

Após construído e validado o problema, chegou-se à etapa de apresentação da situação aos alunos, assim as informações foram repassadas e o funcionamento da metodologia ABP foi explicada.

Neste ponto, também se discutiu brevemente sobre os conceitos de gestão da produção envolvidos na situação. Os alunos, então, foram divididos em duplas ou trios que deveriam utilizar seus conhecimentos prévios no assunto e realizar pesquisas sobre o tema, de forma a melhorar ou solucionar o problema apresentado. O problema idealizado funcionou como o nível 1 de dificuldade, sendo adaptado durante o experimento para os níveis 2 e 3 . Cada nível funcionou como um ciclo de aprendizado da ABP, iniciando na identificação do cenário e finalizando na avaliação do processo de aprendizagem. Os estudantes tiveram 2 semanas para 
desenvolver as soluções e os resultados encontrados ao fim de cada nível foram apresentados e discutidos. Os níveis estão descritos nas próximas etapas.

\section{Nível 1: Organizando o Processo}

No Nível, os alunos modelaram e simularam um novo layout para a empresa de modo que ela conseguisse atender o maior número de pedidos possível, respeitando às restrições do processo. Para isso, cada equipe recebeu um arquivo com a planta 3D do escritório e dos móveis (compatível com o Flexsim), então foi dado início ao ciclo de aprendizagem. Os estudantes tiveram entre 1 e 2 semanas para desenvolver as soluções e os resultados encontrados ao fim do nível foram apresentados e discutidos em sala de aula.

\section{Nível 2: Problemas com Funcionários}

No Nível 2, surgiram novas restrições no problema, aumentando a complexidade da simulação e, consequentemente, requerendo maiores conhecimentos técnicos dos alunos. O nível teve como desafio resolver os novos problemas de layout e atender aos pedidos dos funcionários, processando o maior número de mercadorias possível. Outro ponto abordado foi a decisão entre o melhor tipo de parada a ser adotado (Restrição 7), para isso os estudantes tiveram que simular o layout com paradas aleatórias e com paradas combinadas, apontando qual foi mais produtivo. As restrições do nível estão apresentadas no Quadro 5.

Quadro 5 - Restrições Nível 2

\begin{tabular}{|c|c|}
\hline Restrições & Descrição \\
\hline 1. & $\begin{array}{l}\text { Quando há muitas mercadorias, a funcionária Vânia ajuda o conferente a realizar a } \\
\text { suas atividades. Por isso, é importante que seus postos de trabalho sejam } \\
\text { próximos. }\end{array}$ \\
\hline 2. & $\begin{array}{l}\text { Paulo e Alessandra são amigos de infância e acabam conversando na maior parte } \\
\text { do tempo de trabalho, atrasando os pedidos. Quando a mesa delas é separada } \\
\text { por outro posto de trabalho, o tempo de processamento cai pela metade. }\end{array}$ \\
\hline 3. & $\begin{array}{l}\text { O gerente é muito ocupado, e acabado levando o dobro do tempo médio dos } \\
\text { outros funcionários para realizar suas atividades. }\end{array}$ \\
\hline 4. & $\begin{array}{l}\text { Após a demissão do antigo digitador, um novo funcionário foi contratado para } \\
\text { ocupador o seu cargo. Devido à falta de experiência com o sistema, ele é } 70 \% \\
\text { mais lento que o operador antigo. }\end{array}$ \\
\hline 5. & $\begin{array}{l}\text { Devido às condições de luminosidade e umidade, o balcão não deve ficar próximo } \\
\text { das janelas. }\end{array}$ \\
\hline 6. & $\begin{array}{l}\text { Os funcionários reclamam bastante da falta de um local onde possam guardar } \\
\text { seus lanches para o intervalo de trabalho. Desta forma, a empresa pretende } \\
\text { instalar um armário com frigobar para saciar as reclamações. O novo móvel terá } \\
1,60 \mathrm{~m} \times 2,5 \mathrm{~m} \times 2,5 \mathrm{~m} \text { e deverá estar localizado estrategicamente. Normalmente } \\
\text { cada funcionário gasta } 10 \text { minutos, por dia, lanchando escritório. Esse tempo é } \\
\text { distribuído durante o dia da seguinte maneira: A primeira pausa ocorre } \\
\text { exponencial aos } 3600 \mathrm{~s} \text {, sem desvio. O tempo entre as pausas segue uma } \\
\text { distribuição normal de } 3600 \mathrm{~s} \text {. com } 360 \mathrm{~s} \text { de desvio. O tempo de parada é } \\
\text { normalmente de } 150 \mathrm{~s} \text { com desvio de } 10 \mathrm{~s} \text {. Todos os funcionários param. Elabore } \\
\text { um modelo onde todos parem ao mesmo tempo e outro onde haja uma diferença } \\
\text { de } 100 \mathrm{~s} \text { nas paradas. Variando de } 3600 \mathrm{~s} \text { a } 3100 \mathrm{~s} \text { (os valores podem se repetir } \\
\text { para diferentes funcionários). O desvio é de } 100 \mathrm{~s} \text {, também. }\end{array}$ \\
\hline 7. & $\begin{array}{l}\text { Para identificar em que etapa do processo a mercadoria se encontra, em etapas } \\
\text { específicas ela recebe etiquetas coloridas. Ao chegar ao balcão, uma etiqueta } \\
\text { amarela, ao passar pelo gerente uma etiqueta azul e após ser supervisionada, } \\
\text { uma etiqueta verde. }\end{array}$ \\
\hline
\end{tabular}




\begin{tabular}{|c|l|}
\hline $\mathbf{8 .}$ & $\begin{array}{l}\text { Amanda esta gestante e não pode ficar andando pelo escritório. Quem está } \\
\text { levando a mercadoria para Alessandra é o assistente, mas ela ainda processa. }\end{array}$ \\
\hline $\mathbf{9 .}$ & $\begin{array}{l}\text { Devido a problemas financeiros, a funcionária Adriana foi demitida. Outro } \\
\text { funcionário deverá desempenhar sua função. }\end{array}$ \\
\hline
\end{tabular}

Fonte: Elaboração própria (2020)

\section{Nível 3: Aumento de Mix de Produtos}

No nível 3, além de lidar com novas restrições no problema (Quadro 6), os alunos deviam tomar decisões estratégicas ao optar pelo funcionamento ou não, durante uma hora extra, para atender a demanda dos clientes. Eles ainda tiveram que estipular qual seria o lucro ou prejuízo decorrente da decisão. Para isso, além das restrições do nível, foram informados alguns dados de funcionamento da empresa, indicados no Quadro 7.

\section{Quadro 6 - Restrições Nível 3}

\begin{tabular}{|c|l|}
\hline Consideração & \multicolumn{1}{c|}{ Descrição } \\
\hline $\mathbf{1 .}$ & $\begin{array}{l}\text { O departamento passou a dividir as mercadorias. Agora são classificadas em: } \\
\text { prioritárias (vermelhas) e normais (brancas). }\end{array}$ \\
\hline $\mathbf{2 .}$ & $\begin{array}{l}\text { O tempo de chegada das mercadorias normais é de }(0,30,0) \text { e o das } \\
\text { prioritárias é (0,100,0), exponencialmente. }\end{array}$ \\
\hline $\mathbf{3 .}$ & $\begin{array}{l}\text { As mercadorias prioritárias não precisam passar pelo assistente, pela } \\
\text { funcionária Amanda e pela funcionária Alessandra. }\end{array}$ \\
\hline $\mathbf{4 .}$ & O arquivo deverá ser dobrado (um arquivo para cada tipo de mercadoria). \\
\hline $\mathbf{5 .}$ & O tamanho do balcão deve ser diminuído pela metade. \\
\hline $\mathbf{6 .}$ & $\begin{array}{l}\text { Deverá ser instalado no escritório um banheiro com tamanho 3,0 (X); 4,58(Y); } \\
\text { 3,0 (Z) (medidas do Flexsim). }\end{array}$ \\
\hline $\mathbf{7 .}$ & $\begin{array}{l}\text { Para ajudar no rastreamento das mercadorias, a empresa resolveu comprar } \\
\text { um sistema de RFID. Para isso serão utilizadas etiquetas digitais (insumo do } \\
\text { processo). Somente as mercadorias prioritárias recebem a etiqueta de } \\
\text { identificação. Um novo posto de trabalho deve ser designado para a } \\
\text { implantacão dessas etiquetas, mas não será contratado nenhum novo } \\
\text { funcionário. A etiquetagem é feita por uma máquina e a mercadoria etiquetada } \\
\text { deverá ser representada por uma esfera rosa. O processo de etiquetagem } \\
\text { dura 15 s. }\end{array}$ \\
\hline $\mathbf{8 .}$ & $\begin{array}{l}\text { As etiquetas chegam exponencialmente em (0,10,0) e o posto de trabalho } \\
\text { deverá ter o mesmo tamanho da mesa da funcionária Vânia. Inicialmente as } \\
\text { etiquetas são representadas por esferas na cor teal. }\end{array}$ \\
\hline $\mathbf{9 .}$ & $\begin{array}{l}\text { Todos os funcionários receberam treinamento e estão levando } 5 \text { s para fazer o } \\
\text { seu processamento. }\end{array}$ \\
\hline
\end{tabular}

Fonte: Elaboração própria (2020)

Quadro 7-Dados Nível 3

\begin{tabular}{|c|l|}
\hline Dados & \multicolumn{1}{|c|}{ Descrição } \\
\hline $\mathbf{1 .}$ & O Valor da hora extra de cada funcionário é $\mathrm{R} \$ 60,00$. \\
\hline $\mathbf{2 .}$ & $\begin{array}{l}\text { Os gastos fixos com iluminação, energia e água são de, aproximadamente, } \mathrm{R} \$ 100,00 \\
\text { por hora. }\end{array}$ \\
\hline $\mathbf{3 .}$ & $\begin{array}{l}\text { O preço de venda das mercadorias normais é de } \mathrm{R} \$ 10,00, \text { por unidade, enquanto da } \\
\text { prioritária é de } \mathrm{R} \$ 20,00 .\end{array}$ \\
\hline $\mathbf{4 .}$ & Todos os funcionários são necessários para o processo funcionar. \\
\hline
\end{tabular}

Fonte: Elaboração própria (2020) 


\section{Avaliação Geral do Experimento}

$\mathrm{Na}$ última etapa, os estudantes avaliaram o experimento, métodos, software e o conhecimento adquirido ao longo das atividades através do formulário apresentado na Figura 5.

Figura 5 - Questionário de avaliação do experimento

1. Você acredita que a Metodologia ABP estimula os alunos em sala de aula? Avalie entre 1 (discordo totalmente) e 5 (concordo totalmente).

2. Você acredita que a utilização dessa metodologia na disciplina de Simulação trouxe resultados positivos? Avalie entre 1 (discordo totalmente) e 5 (concordo totalmente).

3. Você acredita que a utilização dessa metodologia ajudaria no ensino de outras disciplinas do curso? Avalie entre 1 (discordo totalmente) e 5 (concordo totalmente).

4. Quais características POSITIVAS da ABP você observou durante o experimento?

5. Quais características NEGATIVAS da ABP você observou durante o experimento?

6. Você acredita que está apto a aplicar os conhecimentos adquiridos na disciplina para a resolução de algum problema real (mesmo simples), em um estágio por exemplo? Avalie entre 1 (discordo totalmente) e 5 (concordo totalmente).

7. Você acredita que a simulação pode auxiliar no ensino de outras disciplinas? Avalie entre 1 (discordo totalmente) e 5 (concordo totalmente).

8. Quais características POSITIVAS da simulação você observou durante o experimento?

9. Quais características NEGATIVAS da simulação você observou durante o experimento?

10. Como você avalia a interface do software? (recursos visuais). Avalie entre 1 (péssima) e 10 (ótima).

11. Como você avalia a usabilidade do software? (Facilidade de utilização do software). Avalie entre 1 (péssima) e 10 (ótima).

12. Como você avalia os recursos oferecidos pelo software? (estatísticas, gráficos etc.). Avalie entre 1 (péssimos) e 10 (ótimos).

13. Qual(is) maior(es) ponto(s) positivo(s) do software para você?

14. Você identificou algum ponto negativo no software? Qual?

15. Você concorda que nas apresentações das simulações houve espaço para discussão sobre conteúdos relativos ao curso? Avalie entre 1 e 5 ;

16. Você concorda que as metodologias em conjunto melhorariam o ensino de outras disciplinas do curso? Avalie entre 1 (discordo totalmente) e 5 (concordo totalmente);

17. Quais disciplinas você acha que poderiam ser beneficiadas?

18. Avaliando todo o experimento, qual nota você daria para a utilização das metodologias em conjunto para o ensino de gestão da produção? Avalie entre 1 (péssima) e 10 (ótima).

Fonte: Elaboração própria (2020)

\section{Resultados e Discussões}

O experimento foi realizado em três semestres letivos e contou com a participação de 20 alunos do curso de Engenharia de Produção, divididos em 10 equipes de trabalho. As duplas representaram $80 \%$ da configuração de trabalho, porém houve um trio e uma equipe unitária.

Quanto ao período em que se encontravam os alunos quando participaram do experimento, a maior adesão ocorreu no quarto semestre ( 9 alunos), seguido dos estudantes do sexto ( 6 alunos) e décimo ( 3 alunos). Também houve participações do quinto e oitavo semestre, 1 aluno cada. Os demais períodos não apresentaram participantes, o que já era esperado, visto que as turmas ocorreram no segundo semestre letivo e os novos estudantes do curso ingressam anualmente. 


\section{Resultados das Simulações}

No Nível 1, o desafio dos participantes foi alterar a posição dos postos de trabalho do escritório de forma a melhorar a produtividade da empresa. Como os recursos utilizados (tempo, pessoas, objetos, etc.) foram os mesmos para todas as equipes, pode-se definir que a quantidade de saídas (mercadorias que concluíram todo o processo) é o indicador que melhor representa a produtividade da empresa. Assim, as equipes com melhor desempenho foram aquelas que tiveram a maior quantidade de saídas ao fim do tempo de simulação. De modo geral, todas as equipes conseguiram aumentar a produtividade do escritório, aumentando o número de saídas de mercadorias.

No Nível 2, além de adaptar a situação a todas as restrições, os alunos tiveram que adicionar tempos de parada para todos os operadores. Dessa forma, eles tiveram que elaborar dois modelos, um com paradas aleatórias (os operadores paravam em momentos diferentes) e um com paradas combinadas (os operadores paravam no mesmo momento). Os dois modelos deveriam ter o mesmo layout e o objetivo era identificar em qual tipo de parada haveria melhor produtividade. Para este nível, as saídas também foram consideradas como o melhor indicador de produtividade. Dessa forma, $70 \%$ das equipes tiveram seus melhores resultados com paradas combinadas, enquanto $30 \%$ tiveram com paradas aleatórias.

No Nível 3, além das novas restrições, os alunos precisaram simular o layout proposto para 6 e 7 horas de trabalho. O objetivo foi fazê-los identificar se valeria a pena ou não, pagar pelo funcionamento de uma hora extra do escritório e estipular qual seria o lucro ou prejuízo da ação. Outro ponto chave dessa fase foi o surgimento das mercadorias prioritárias, que trouxeram algumas alterações ao processo geral.

\section{Avaliação pelos Participantes}

Finalizados os três níveis, os estudantes avaliaram, através do questionário da Figura 9 diversos pontos do experimento, como utilização do ABP, Simulação, Flexsim e o Experimento de forma geral. Dentre os 20 participantes, 15 responderam à pesquisa, representando $75 \%$ do grupo.

O primeiro ponto a ser avaliado foi a utilização Metodologia ABP na figura 6 .

Figura 6 - Avaliação da ABP quanto ao estímulo em sala de aula Você acredita que essa metodologia ativa de ensino estimula os alunos em sala de aula?

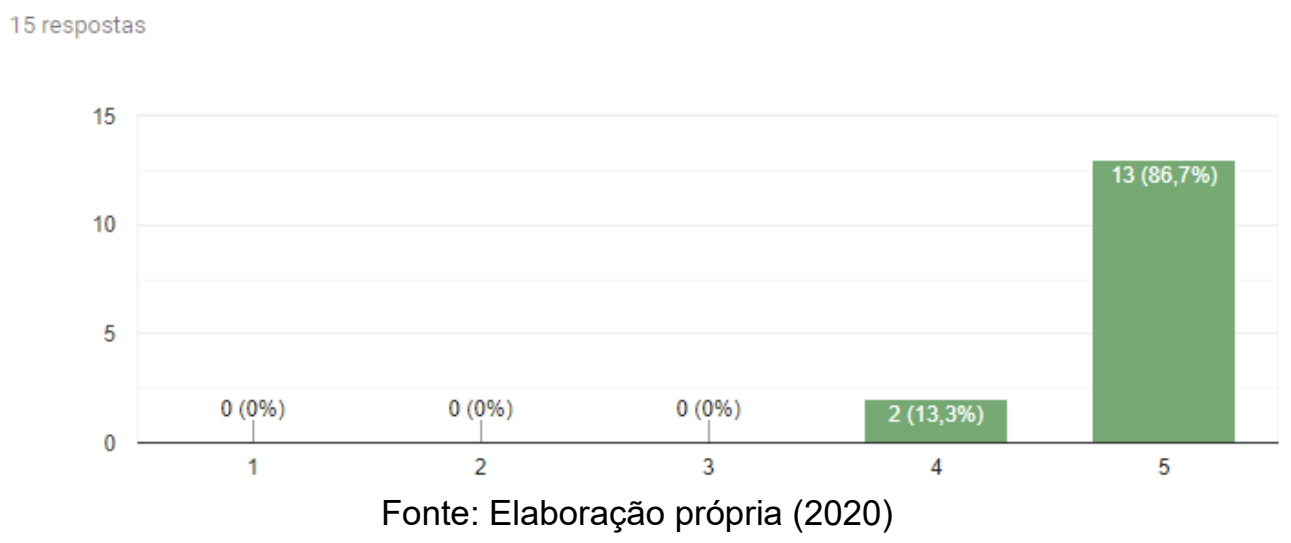


Como está apresentado na Figura $8,86,7 \%$ dos participantes concordaram totalmente que a ABP estimula os alunos em sala de aula, enquanto $13,3 \%$ concordaram parcialmente. Segundo os estudantes, o estímulo surge principalmente da abordagem prática do método, do sentimento de competição pelos melhores resultados e do tipo de questão apresentada (baseada em problemas que encontrarão na vida real).

Para a utilização da ABP na disciplina de simulação, $100 \%$ dos alunos concordaram que o método trouxe resultados positivos na Figura 7.

Figura 7 - Avaliação da ABP na disciplina de simulação

Você acredita que a utilização dessa metodologia na disciplina de Simulação trouxe resultados positivos?

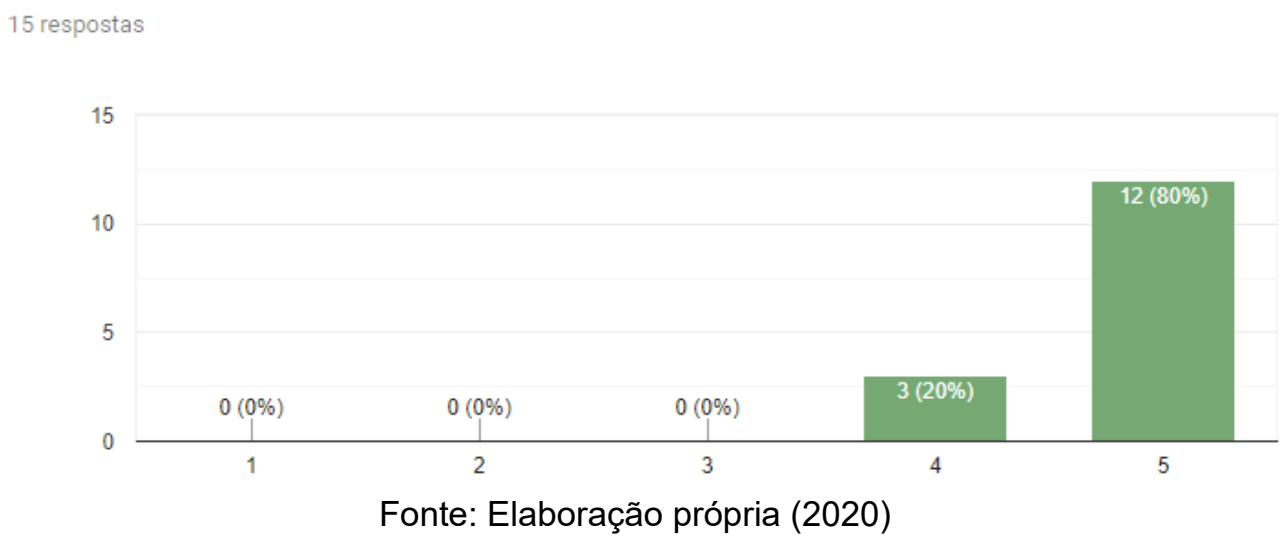

No geral, para os participantes, os maiores pontos positivos da utilização da metodologia foram:

a. O incentivo da capacidade de análise dos alunos;

b. O estímulo ao estudo independente e busca por soluções práticas;

c. O incentivo à aprendizagem colaborativa;

d. A aplicação prática de conceitos teóricos;

e. O maior dinamismo na sala de aula;

f. A resolução de problemas reais ou similares à realidade;

g. Os feedbacks por parte do professor e monitores.

Não foram enunciados muitos pontos negativos sobre a metodologia, contudo, a dificuldade em dividir as tarefas/atividades dentro da equipe e a ausência da abordagem de alguns conceitos necessários a resolução dos problemas, foram citadas como pontos de melhoria.

Quanto à possibilidade de ajuda em outras disciplinas (Figura 8), 93,3\% dos alunos concordaram que a metodologia seria benéfica no ensino de outras matérias, enquanto um participante mostrou-se imparcial. Para eles, seria interessante a aplicação em disciplinas que demandam conhecimentos mais práticos, específicos do curso. 
Figura 8 - Avaliação da ABP no ensino de outras disciplinas Você acredita que a utilização dessa metodologia ajudaria no ensino de outras disciplinas do curso?

15 respostas

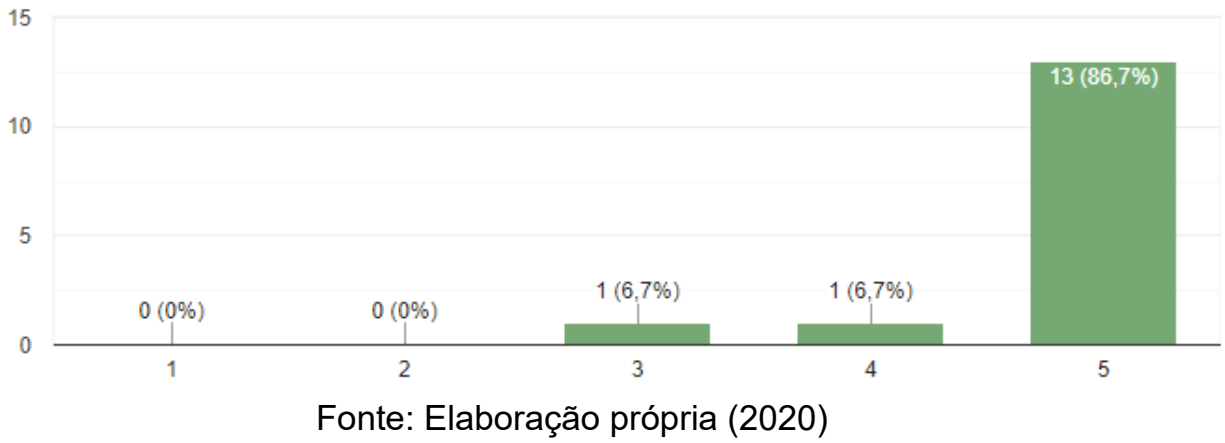

O segundo ponto a ser avaliado foi o uso da simulação. Ao fim do experimento, $73,3 \%$ dos participantes concordaram que se sentiam aptos a utilizar a simulação para resolver algum problema, mesmo simples (Figura 9). Os outros 26,7\% mostraram-se imparciais. Para alguns estudantes faltaram discussões em sala de alguns conceitos necessários à disciplina e à resolução dos problemas.

Figura 9 - Avaliação da aplicação dos conhecimentos adquiridos na disciplina Você acredita que está apto a aplicar os conhecimentos adquiridos na disciplina para a resolução de algum problema real (mesmo simples), em um estágio por exemplo?

15 respostas

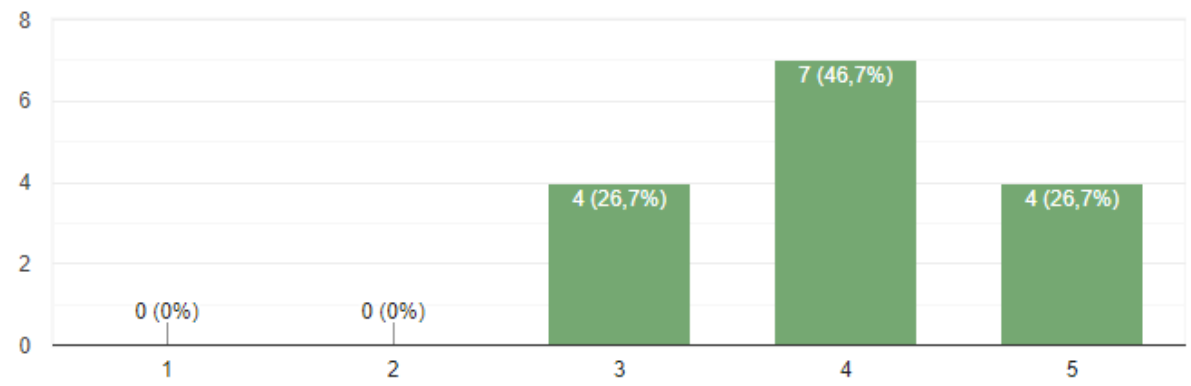

Fonte: Elaboração própria (2020)

Como mostrado na Figura $10,86,7 \%$ dos participantes concordaram que a simulação pode auxiliar no ensino de outras disciplinas, destes, $40 \%$ concordaram parcialmente. $13,3 \%$ mostraram-se imparciais na questão. 
Figura 10 - Avaliação da simulação no ensino de outras disciplinas Você acredita que a simulação pode auxiliar no ensino de outras disciplinas?

15 respostas

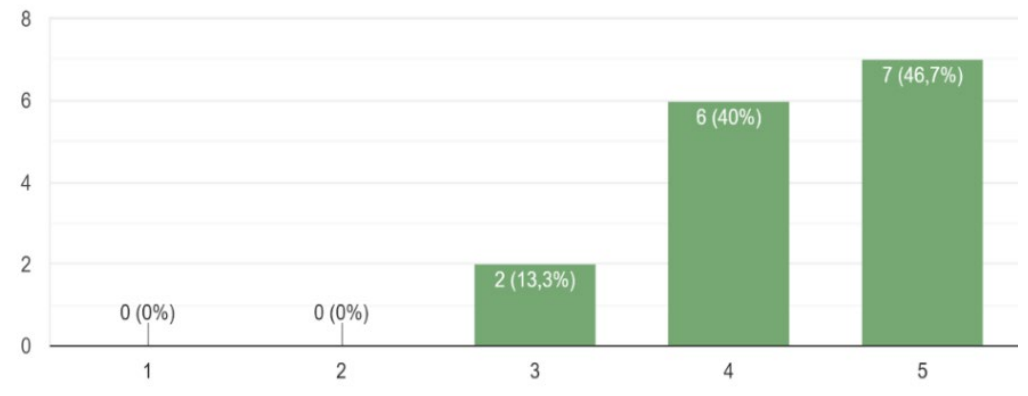

Fonte: Elaboração própria (2020)

No geral, para os participantes, os maiores pontos positivos da utilização da simulação, foram:

a. A possibilidade de testar diferentes hipóteses;

b. Constatar onde estavam os gargalos do processo;

c. A obtenção de vários tipos de dados e estatísticas;

d. A possibilidade de alterações de diversões parâmetros;

e. Aliar dados com a tomada de decisão.

Já os pontos negativos, mais citados foram:

a. A demora para elaboração do modelo;

b. A dificuldade de parametrizar objetos;

c. A dificuldade de interpretar os dados da simulação.

Diferentemente das outras questões, para a avaliação do software foram utilizadas escalas com notas de 1 (péssimo) a 10 (ótimo).

O primeiro ponto avaliado foi a interface do Flexsim. Neste quesito, todos os participantes avaliaram o software com notas acima ou igual a 7, como apresentado na Figura 11. $40 \%$ dos votantes deram nota 9 para a interface, enquanto a média geral foi de 8,8 . O visual 3D foi o principal responsável pelo bom desempenho no critério. 
Figura 11 - Avaliação da interface do Software

Como você avalia a interface do software? (recursos visuais)

15 respostas

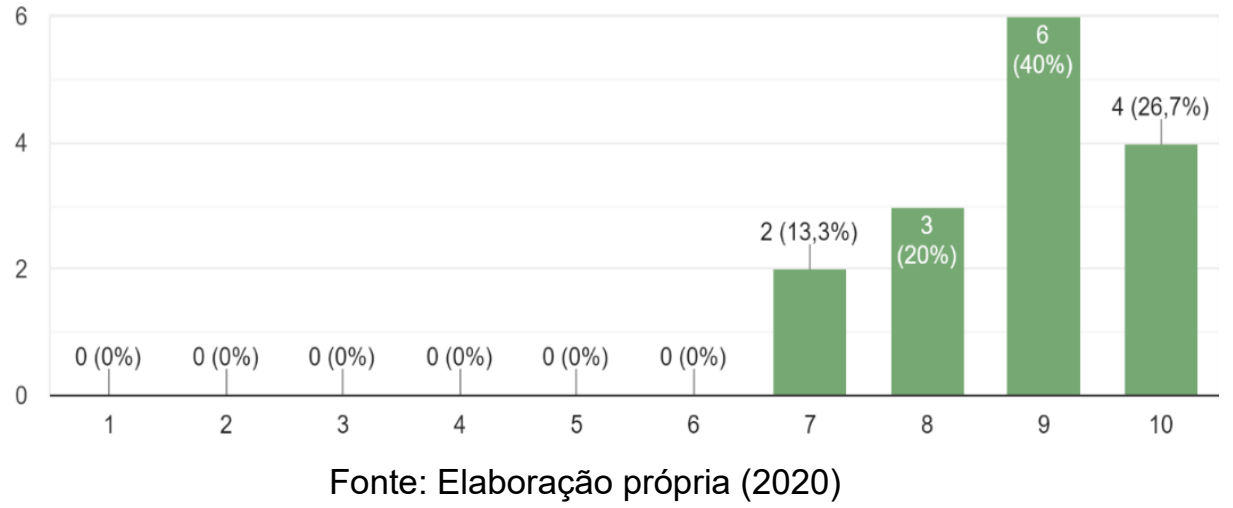

Para a usabilidade (Figura 12), a maioria dos alunos $(46,7 \%)$ avaliaram o Flexsim com nota 7. O segundo maior percentual foi de notas $8(33,3 \%)$, contudo houve notas abaixo de 7. A média geral no quesito foi 7,2. Para os estudantes, mesmo o software sendo bastante intuitivo, ele requer um bom treinamento para que se possa elaborar os modelos e utilizar as ferramentas adicionais.

Figura 12 - Avaliação da usabilidade do software

Como você avalia a usabilidade do software? (Facilidade de utilização do software)

15 respostas

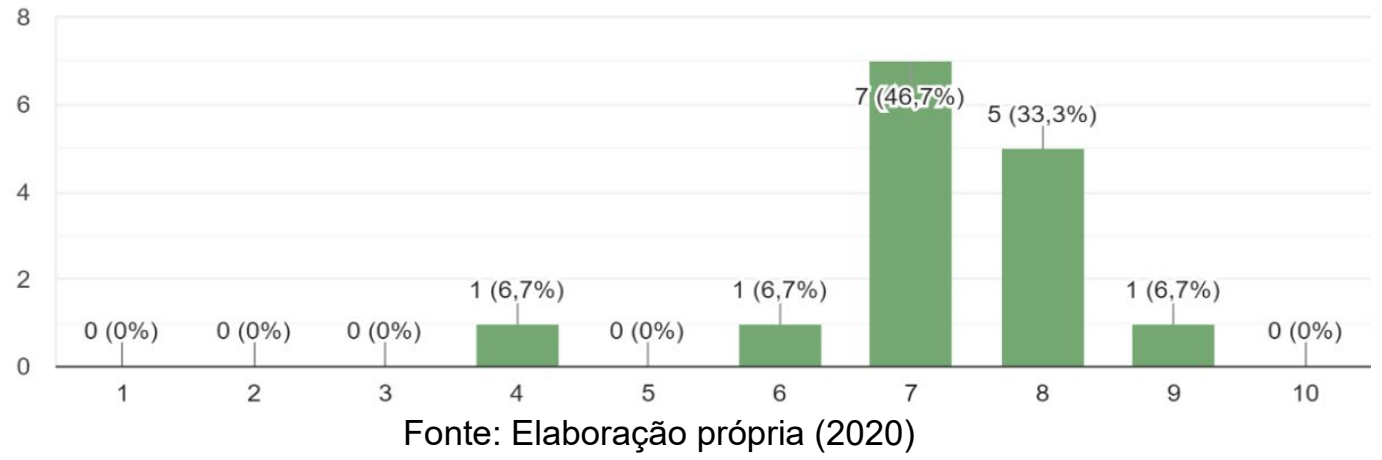

Os recursos tiveram, no geral, ótima avaliação, com média 8,53 e 40\% dos participantes avaliando o critério com nota 8 (Figura 13). Os destaques foram a dashboard com gráficos e as possibilidades de parametrização dos objetos. 
Figura 13 - Avaliação dos recursos do software

Como você avalia os recursos oferecidos pelo software? (estatísticas, gráficos, etc)

15 respostas

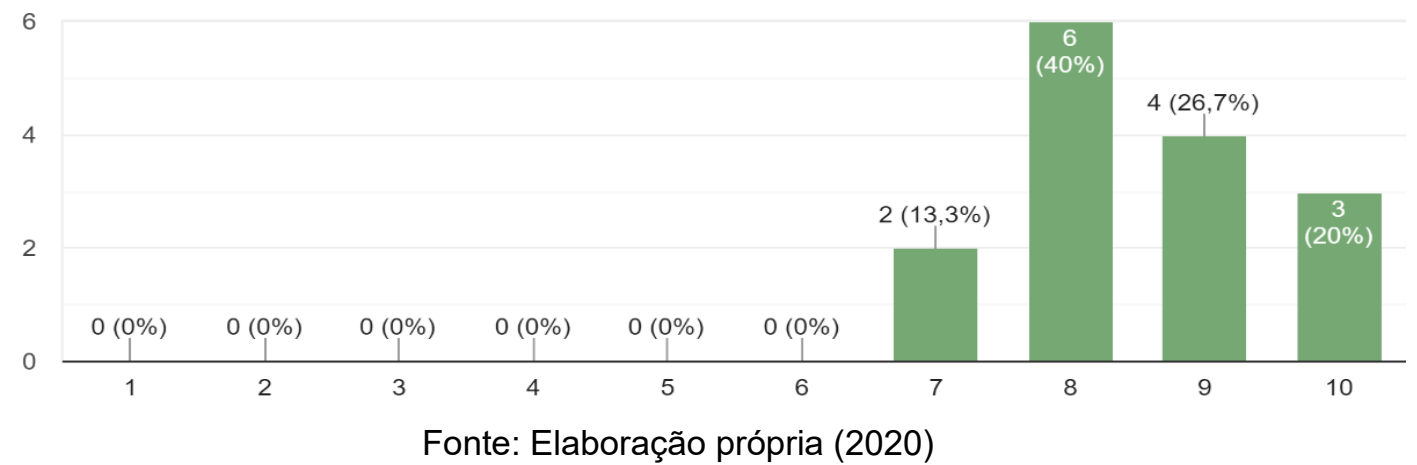

Para os participantes, os maiores pontos positivos do software são:

a. A interface gráfica;

b. A flexibilidade com outros softwares;

c. A abrangência, podendo ser utilizado para resolver desde problemas simples até questões mais complexas;

d. A facilidade de uso;

e. Gráficos e estatísticas disponíveis ao longo da simulação através da dashboard;

f. A possibilidade de alteração visual dos objetos, possibilitando maior personalização do modelo;

g. A variedade de parâmetros números dos objetos que podem ser ajustados.

Por outro lado, os pontos negativos mais citados foram:

a. A limitação decorrente da versão estudantil, visto que o acesso à versão full só era possível no laboratório da IES;

b. Pouco material didático disponível sobre como utilizar o programa;

c. Para simulações mais complexas, o computador que deve ser potente, se não haverá travamentos e "bugs";

d. A falta de objetividade do software ao apontar erros na simulação.

De maneira geral, todos os alunos concordaram que houve espaço para discussão sobre conteúdos relativos à gestão da produção ao longo do experimento (Figura 14). Destes, $66,7 \%$ totalmente e 33,3\% parcialmente. 
Figura 14 - Avaliação da discussão sobre conteúdos

Você concorda que nas apresentações das simulações houve espaço para discussão sobre conteúdos relativos ao curso?

15 respostas

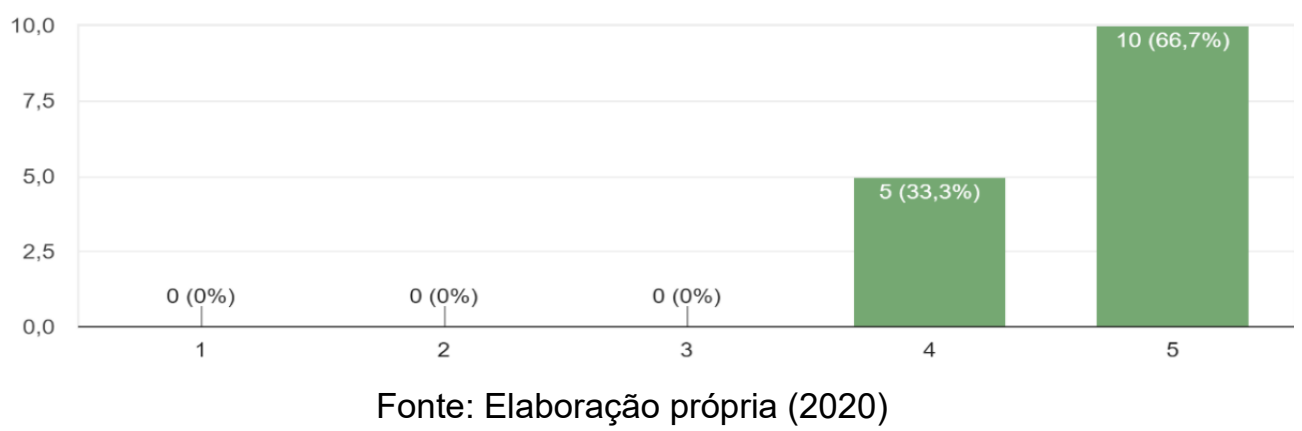

Quanto a utilização das metodologias em conjunto para ensino de outras disciplinas, $73,3 \%$ dos participantes concordaram totalmente que seria benéfico para a didática em sala de aula, enquanto $26,7 \%$ concordaram parcialmente (Figura 15).

Figura 15 - Avaliação das metodologias em conjunto para ensino de outras disciplinas Você concorda que as metodologias em conjunto melhorariam o ensino de outras disciplinas do curso?

15 respostas

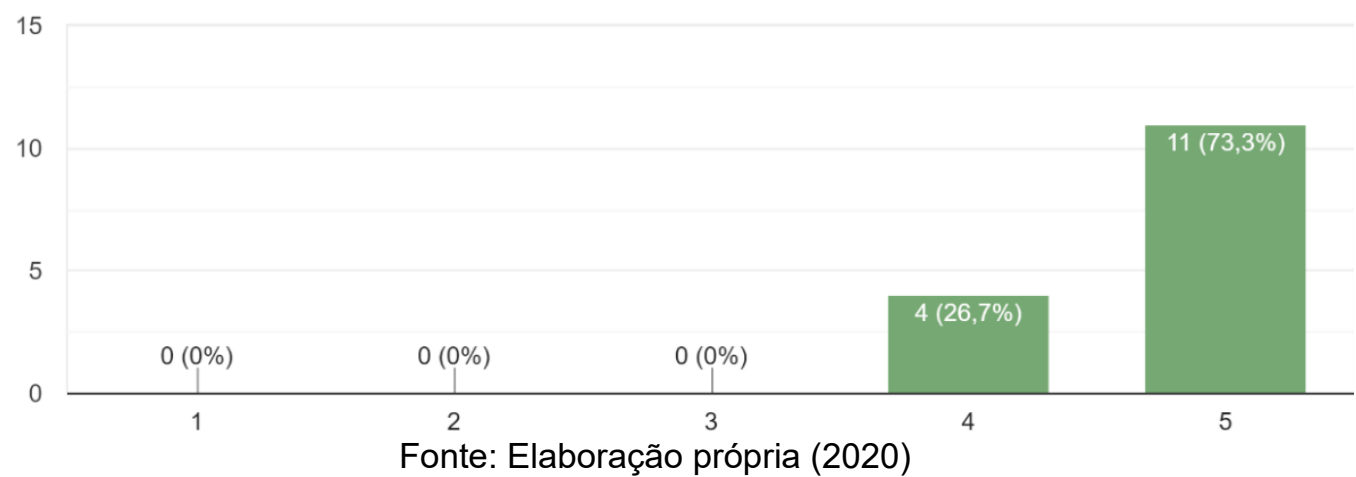

As disciplinas da grade curricular que poderiam ser beneficiadas também foram apontadas pelos alunos, os dados estão apresentados na Figura 16. Logística, teve o maior número de votantes, onde $93,3 \%$ dos participantes concordaram que a disciplina poderia utilizar as metodologias de forma positiva. Em seguida estão: Planejamento e Controle da Produção - PCP (80\%), Projeto Industrial $(66,7 \%)$ Pesquisa Operacional (60\%), Sistemas e Métodos de Trabalho (53,3\%), Controle Estatístico do Processo (53,3\%), Programação (33,3\%), Ergonomia (26,7\%) e Engenharia Econômica/Custos (6,7\%). 
Figura 16 - Avaliação das disciplinas que poderiam ser beneficiadas Quais disciplinas você acha que poderiam ser beneficiadas?

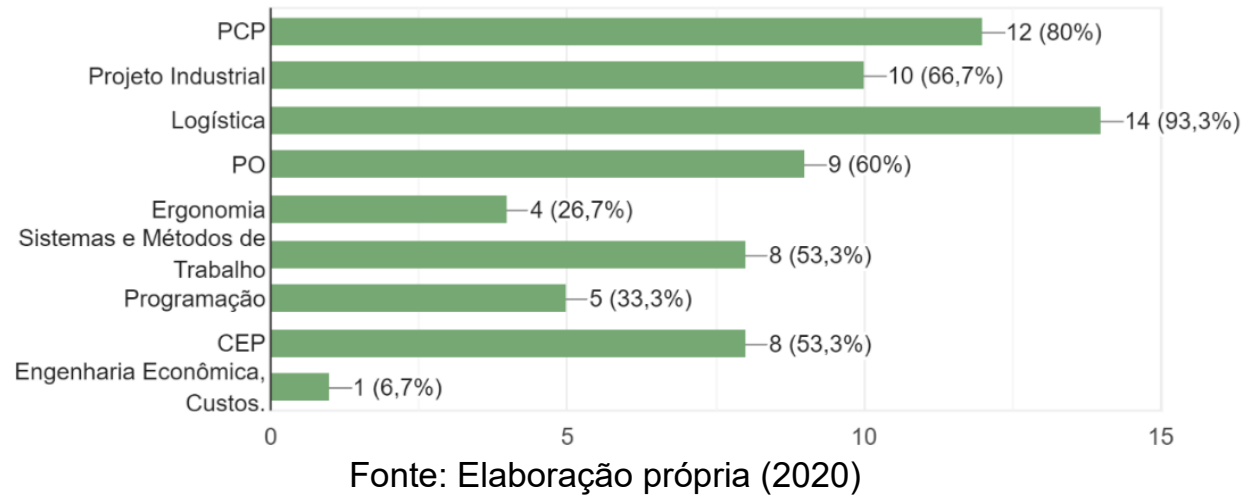

Finalmente, os alunos avaliaram com notas entre 0 e 10 (Figura 17), a utilização das metodologias para ensino de Gestão da Produção. $60 \%$ dos participantes avaliaram a experimento com nota 9 , enquanto $26,7 \%$ deram nota máxima. A média geral foi de 9,13, um resultado excelente.

Figura 17 - Avaliação geral das metodologias em conjunto

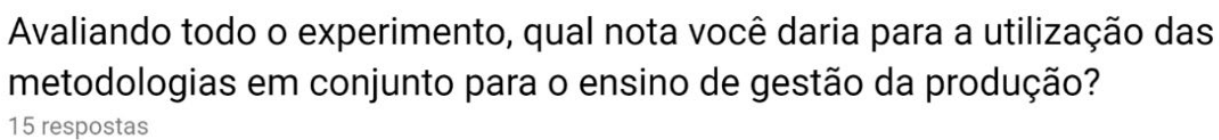

15 respostas

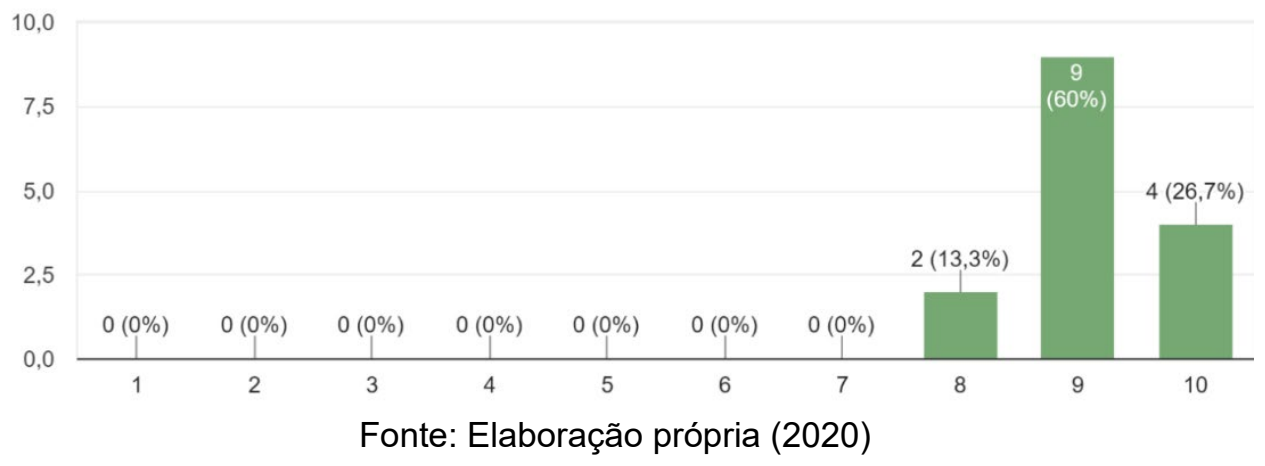

Na Tabela 1, está apresentado o resumo das avaliações dos participantes, bem como o desempenho percentual em relação à nota máxima. $\mathrm{O}$ critério com melhor avaliação foi o estímulo em sala de aula da Metodologia ABP, com 97,40\% da nota máxima. O pior desempenho ocorreu em termos da usabilidade do simulador, $72 \%$ da nota máxima. Todos os outros quesitos obtiveram desempenho superior à $80 \%$ do máximo.

Tabela 1 - Resumo das avaliações

\begin{tabular}{clccc}
\hline \multirow{2}{*}{ Tópico } & \multicolumn{1}{c}{ Critério } & $\begin{array}{c}\text { Nota } \\
\text { Alcançada }\end{array}$ & $\begin{array}{c}\text { Nota } \\
\text { Máxima }\end{array}$ & Desempenho \\
\hline \multirow{3}{*}{ ABP } & Estímulo em sala de aula & 4,87 & 5,0 & $97,40 \%$ \\
& Utilização na disciplina de simulação & 4,80 & 5,0 & $96,00 \%$ \\
& Auxílio no ensino de outras disciplinas & 4,80 & 5,0 & $96,00 \%$ \\
\multirow{2}{*}{ Simulação } & Conhecimento adquirido & 4,00 & 5,0 & $80,00 \%$ \\
& Auxílio no ensino de outras disciplinas & 4,33 & 5,0 & $86,60 \%$
\end{tabular}




\begin{tabular}{clccc} 
Flexsim & Interface & 8,80 & 10,0 & $88,00 \%$ \\
& Usabilidade & 7,20 & 10,0 & $72,00 \%$ \\
& $\begin{array}{l}\text { Recursos } \\
\text { Espaço para discussão sobre } \\
\text { conteúdos relativos à Engenharia de }\end{array}$ & 8,53 & 10,0 & $85,30 \%$ \\
$\begin{array}{l}\text { Produção } \\
\text { Geral }\end{array}$ & 4,67 & 5,0 & $93,40 \%$ \\
$\begin{array}{l}\text { Utilização das metodologias em } \\
\text { conjunto para auxílio no ensino de } \\
\text { outras disciplinas }\end{array}$ & 4,73 & 5,0 & $94,60 \%$ \\
$\begin{array}{l}\text { Utilização das metodologias em } \\
\text { conjunto para ensino de Gestão da } \\
\text { Produção. }\end{array}$ & 9,13 & 10,0 & $91,30 \%$ \\
\hline
\end{tabular}

Fonte: Elaboração própria (2020)

\section{Conclusões}

Diante dos novos desafios propostos pelo mercado de trabalho, relativos à necessidade da formação de profissionais com maior visão sistêmica e capacidade de resolução de problemas, este trabalho propôs o estudo e descreveu os resultados encontrados em sala de aula para a aplicação, em conjunto, de métodos de ensino considerados promissores. Dessa forma, a SED, através do Software Flexsim, e a ABP foram utilizadas como instrumentos de ensino de Gestão da Produção para alunos de um curso de Engenharia de Produção, em uma IES pública.

Quanto à metodologia utilizada na pesquisa, pode-se concluir que houve um desempenho satisfatório, resultado de uma divisão de etapas bem estruturada e funcional. A quantidade de aulas expositivas, características do método tradicional de ensino, foram bastante reduzidas e utilizadas somente nas etapas da metodologia 1 e 2, as quais foram bem avaliadas pelos alunos.

Cada nível proposto funcionou como um ciclo de aprendizado da ABP, iniciando na identificação do cenário e finalizando na avaliação do processo de aprendizagem. Dessa forma, pode-se afirmar que o estudo alcançou com sucesso seu objetivo a partir da utilização da metodologia ABP, por meio da formulação de problemas que envolvam conceitos e ferramentas de gestão da produção e a SED, através do Flexsim, para a simulação de soluções para os problemas apresentados.

Com relação ao uso do $\mathrm{ABP}$, os participantes concordaram (parcialmente ou completamente) sobre os resultados positivos para a disciplina de simulação e, possivelmente, em outras disciplinas do curso. Foram apresentados pontos positivos como o estímulo à capacidade analítica dos alunos e ao aprendizado colaborativo e como ponto negativo foi elencado a falta de abrangência de alguns assuntos.

Quanto ao uso da SED, $73,7 \%$ dos avaliadores concordaram que estavam aptos a aplicar o conhecimento adquirido na disciplina para a resolução de problemas, enquanto $86,7 \%$ concordaram que a SED pode ajudar no ensino de outras disciplinas. A possibilidade de testar novos cenários e aliar dados à tomada de decisão foram avaliados como pontos positivos, enquanto a demora para elaboração do modelo e dificuldade na interpretação de dados, como negativos.

Para o Flexsim, foram avaliados três critérios: interface, usabilidade e recursos oferecidos. O simulador foi bem avaliado nos três quesitos, recebendo notas 8,8; 
7,2 e 8,53; respectivamente. Para os avaliadores, o software apresenta vários pontos positivos como visual 3D, abrangência, flexibilidade e facilidade de uso; porém tem seus recursos limitados pela versão estudantil (gratuita).

Para o experimento em geral, os avaliadores concordaram que houve espaço para discussão sobre conteúdos relativos à gestão da produção e que as metodologias utilizadas em conjunto podem beneficiar outras disciplinas, como Logística, Projeto Industrial, dentre outras. Finalmente, a nota média para a aplicação das metodologias foi de 9,13, caracterizando um excelente resultado.

\section{Referências}

ARAÚJO, L. C. G. Organização, Sistemas e Métodos e as Ferramentas de Gestão Organizacional. São Paulo: Atlas, 2002.

BRASIL. Conselho Nacional de Educação. Câmara de Conselho Superior. Resolução CNE/CES 11, de 11 de março de 2002, institui as Diretrizes Curriculares Nacionais do Curso de Graduação em Engenharia. Disponível em: <http://portal.mec.gov.br/cne/arquivos/pdf/CES112002.pdf>. Acesso em: 25 ago. 2018.

BORGES NETO, M.; ALMEIDA, N. Perspectivas para engenharia nacional, desafios e oportunidades. Revista de Ensino de Engenharia, v. 32, n. 3, 2013.

CHEN, L.; HU, D.; XU, T. Highway Freight Terminal Facilities Allocation based on Flexsim. In: 13th COTA International Conference of Transportation Professionals. Automobile College of Chang, Shaanxi, China, Elsevier, v. 96, p. 368381, 2013.

CORREAA, H. L.; CORRÊA, C. A. Administração de produção e operações: manufatura e serviços: uma abordagem estratégica. 4 ed. São Paulo: Atlas, 2017.

DO AMARAL, B. H. Aplicação da simulação de eventos discretos (SED) e da aprendizagem baseada em problema (ABP) no ensino de gestão da produção. Trabalho de Conclusão de Curso (Graduação em Engenharia de Produção Mecânica). Centro de Tecnologia, Universidade Federal do Ceará, Ceará, 2018.

ECHAVARRIA, M. V. Problem based learning application in engineering. Revista EIA, n. 18, p. 85-95, 2010.

ESCRIVÃO FILHO, E.; RIBEIRO, L. R. C. Aprendendo com PBL - aprendizagem baseada em problema: relato de uma experiência em cursos de Engenharia da EESC-USP. Revista Minerva, v. 6, p. 23-30, 2009.

HEINIG, O. L. O. M.; FRANZEN, B. A. A leitura e a escrita na engenharia: construindo intersecções entre o mundo do trabalho e a academia. Revista de Ensino de Engenharia, v. 32, n. 2, p. 9-18, 2013.

HMELO-SILVER, C. E. Problem-based learning: what and how do students learn? Educational Psychology Review, v. 16, n.3, p. 235-266, 2004.

KELTON, D.; SADOWSKI, D. A.; SADOWSKI, R. P. Simulation with ARENA. New York: McGraw-Hill, 2010. 
KHALIL, R.F. O uso da tecnologia de simulação na prática docente do ensino superior. In: XVI ENDIPE - Encontro Nacional de Didática e Prática de Ensino. Anais. Campinas, UNICAMP, 2012.

MASSON, T. J. Metodologia de ensino: aprendizagem Baseada em Projetos (PBL). In: XL Congresso Brasileiro de Educação em Engenharia. Anais. Belém, ABENGE, 2012.

MORAN, J. M. Mudando a educação com metodologias ativas. In: SOUZA, C. A.; MORALES, O. E. T. (Org.). Convergências midiáticas, educação e cidadania: aproximações jovens, v. 2. Ponta Grossa: Foca Foto-PROEX/UEPG, Coleção Mídias Contemporâneas, 2015.

MONTEIRO, S. B. Uma Nova Abordagem de Ensino de Engenharia: Aprendizagem Baseada em Projetos (PjBL) na Disciplina PSP1 da Curso de Engenharia de Produção da UnB. In: XXXIX Congresso Brasileiro de Educação em Engenharia. Anais. Blumenau, ABENGE, 2011.

RANGEL, J.J.; SOUZA, A.; BASTOS, P.J.T.; BAPTISTA, R. C. T. Simulação a Eventos Discretos para Treinamento em Sistemas de Controle. Revista Pesquisa Operacional para o Desenvolvimento, v.4, n.1, p. 97-111, 2012.

RIBEIRO, L. R. Aprendizagem baseada em problemas (PBL) na educação em Engenharia. Revista de Ensino de Engenharia, v. 27, p. 23-32, 2008.

KRAJEWSKI, L. J.; RITZMAN, L. P; MALHOTRA, M. K. Administração da produção e operações. 8. ed. São Paulo: Pearson Prentice Hall, 2009.

SANTANA, F. S. A função social das instituições particulares de ensino no cenário educacional brasileiro. Colloquium Humanarum, v. 8, n. 2, p. 09-21, 2011.

SLACK, N.; CHAMBERS, S.; HARLAND, C.; HARRISON, A.; JOHNSTON, R. Administração da produção. 3 ed. São Paulo: Editora Atlas, 2009.

STIVARI, T; GAMEIRO, A. A simulação de eventos discretos como ferramenta de avaliação e planejamento da produção animal. Tese (Pós-graduação em Nutrição e Produção Animal) - Faculdade de Medicina Veterinária e Zootecnia, Universidade de São Paulo, Pirassununga, 2015.

Recebido: 07/04/20

Aprovado: 15/05/20

Como citar: PONTES, H. L. J.; AMARAL, B. H.; RODRIGUES, M. V. O ensino de Gestão da Produção utilizando a Aprendizagem Baseada em Problemas (ABP) e a Simulação de Eventos Discretos (SED). Revista de Estudos e Pesquisa sobre Ensino Tecnológico (EDUCITEC), v. 6, e124420, 2020

Direito autoral: Este artigo está licenciado sob os termos da Licença Creative CommonsAtribuição 4.0 Internacional.

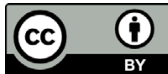

